\title{
Population living on permafrost in the Arctic
}

\author{
Justine Ramage ${ }^{1}$ (D) - Leneisja Jungsberg ${ }^{1,2} \cdot$ Shinan Wang ${ }^{1}$. \\ Sebastian Westermann ${ }^{3} \cdot$ Hugues Lantuit ${ }^{4,5} \cdot$ Timothy Heleniak $^{1}$
}

Accepted: 25 November 2020/ Published online: 6 January 2021

(C) The Author(s) 2021

\begin{abstract}
Permafrost thaw is a challenge in many Arctic regions, one that modifies ecosystems and affects infrastructure and livelihoods. To date, there have been no demographic studies of the population on permafrost. We present the first estimates of the number of inhabitants on permafrost in the Arctic Circumpolar Permafrost Region (ACPR) and project changes as a result of permafrost thaw. We combine current and projected populations at settlement level with permafrost extent. Key findings indicate that there are 1162 permafrost settlements in the ACPR, accommodating 5 million inhabitants, of whom 1 million live along a coast. Climate-driven permafrost projections suggest that by $2050,42 \%$ of the permafrost settlements will become permafrost-free due to thawing. Among the settlements remaining on permafrost, $42 \%$ are in high hazard zones, where the consequences of permafrost thaw will be most severe. In total, 3.3 million people in the ACPR live currently in settlements where permafrost will degrade and ultimately disappear by 2050 .
\end{abstract}

Keywords Arctic circumpolar permafrost region - Arctic settlements - Arctic population · Permafrost thaw $\cdot$ Arctic infrastructure $\cdot$ Risk

\section{Introduction}

The unprecedented rise in air surface temperature observed in the Arctic causes dramatic changes on the components of the cryosphere, including permafrost.

Justine Ramage

justine.ramage@nordregio.org

1 Nordregio, Stockholm, Sweden

2 Institute for Natural Resources and Geosciences, Copenhagen University, Copenhagen, Denmark

3 Department of Geosciences, University of Oslo, Oslo, Norway

4 Alfred Wegener Institute Helmholtz Centre for Polar and Marine Research, Potsdam, Germany

5 Department for Earth Sciences, University of Potsdam, Potsdam, Germany 
Permafrost is ground (soil, sediment, or rock) that remains at or below $0{ }^{\circ} \mathrm{C}$ for at least two consecutive years (Van Everdingen 2005). The permafrost region covers about $24 \%$ of the Earth's land surface in the Northern Hemisphere, including large areas of the Arctic (Gruber 2012). Over the last two decades, Arctic surface air temperature has increased by more than double the global average. Near-surface permafrost in the Arctic has warmed by more than $0.5^{\circ} \mathrm{C}$ between 2009 and 2017 (Biskaborn et al. 2019), triggering permafrost thaw. This thaw causes changes in the ecosystems on which Arctic inhabitants are directly dependent. The impacts of permafrost thaw in the Arctic are becoming more visible, leading to increased scientific, economic, and political attention. The impacts on communities (Allard et al. 2012; Ford and Pearce 2010) include, e.g., destabilization of infrastructure (O'Garra 2017; Streletskiy et al. 2019), reduction in country food accessibility (Berkes and Jolly 2000; Wesche and Chan 2010), and declining health conditions (Sharma 2010). While people in the Arctic are adaptable to climatic variability, financial, institutional, and knowledge constraints are limiting their adaptive capacity (Ford et al. 2010).

As permafrost thaw accelerates in the Arctic, the need for studies looking at the impact of permafrost thaw on permafrost societies and economies increases. Seventy percent of the pan-Arctic residential, transportation, and industrial infrastructure is in areas with high potential for near-surface permafrost thaw by 2060 (Hjort et al. 2018). The changing environmental conditions not only affect people by damaging infrastructure but also impact the livelihoods and cultural activities of the populations living on permafrost (Ford and Pearce 2010). Arctic communities have a strong relationship with the land and the sea, and traditional activities such as hunting and fishing continue to be important for much of the population (Duhaime et al. 2004).

To understand the magnitude of the forthcoming challenges related to permafrost thaw in the Arctic, it is crucial to estimate the number of people who will be impacted. While most literature suggests that approximately 4 million people live in the commonly defined administrative Arctic region (NSIDC 2019; Nymand Larsen 2014), there is yet no estimate of the number of people living on permafrost in the Arctic. To address this, we define the Arctic Circumpolar Permafrost Region (ACPR) and contribute data on the number of people residing on permafrost in the Arctic. We combine administrative boundaries with current permafrost extent to define permafrost settlements and calculate the population living on permafrost. To fully grasp the risk of the anticipated change in permafrost in the ACPR, we combine a model projecting permafrost extent to 2060 with population projections from regional and national statistical institutes. The outcome forecasts the possible impact of permafrost loss on the population in the ACPR by 2050 .

\section{Study area}

Our study area comprises the ACPR (Fig. 1). In defining this region, we developed a strategy for converging demographic and northern circumpolar permafrost extent datasets. We used the definition of the Arctic from the Arctic Human Development Report (AHDR, Einarsson et al. 2004) and adapted it to the scope of this study, to (1) reflect current Arctic geopolitical divisions; and (2) focus on the northern circumpolar permafrost region. As a result, a few regions comprising large areas underlain by 
permafrost were added to the definition of the Arctic from the AHDR in order to conform to this paper's focus on permafrost - the entire regions of Kamchatka, Magadan, Khanty-Mansi, the Sakha Republic, and Krasnoyarsk (Russian Federation).

The regions and countries included in the definition of the ACPR are Alaska (USA); Yukon, the Northwest Territories, Nunavut, Newfoundland and Labrador, Northern

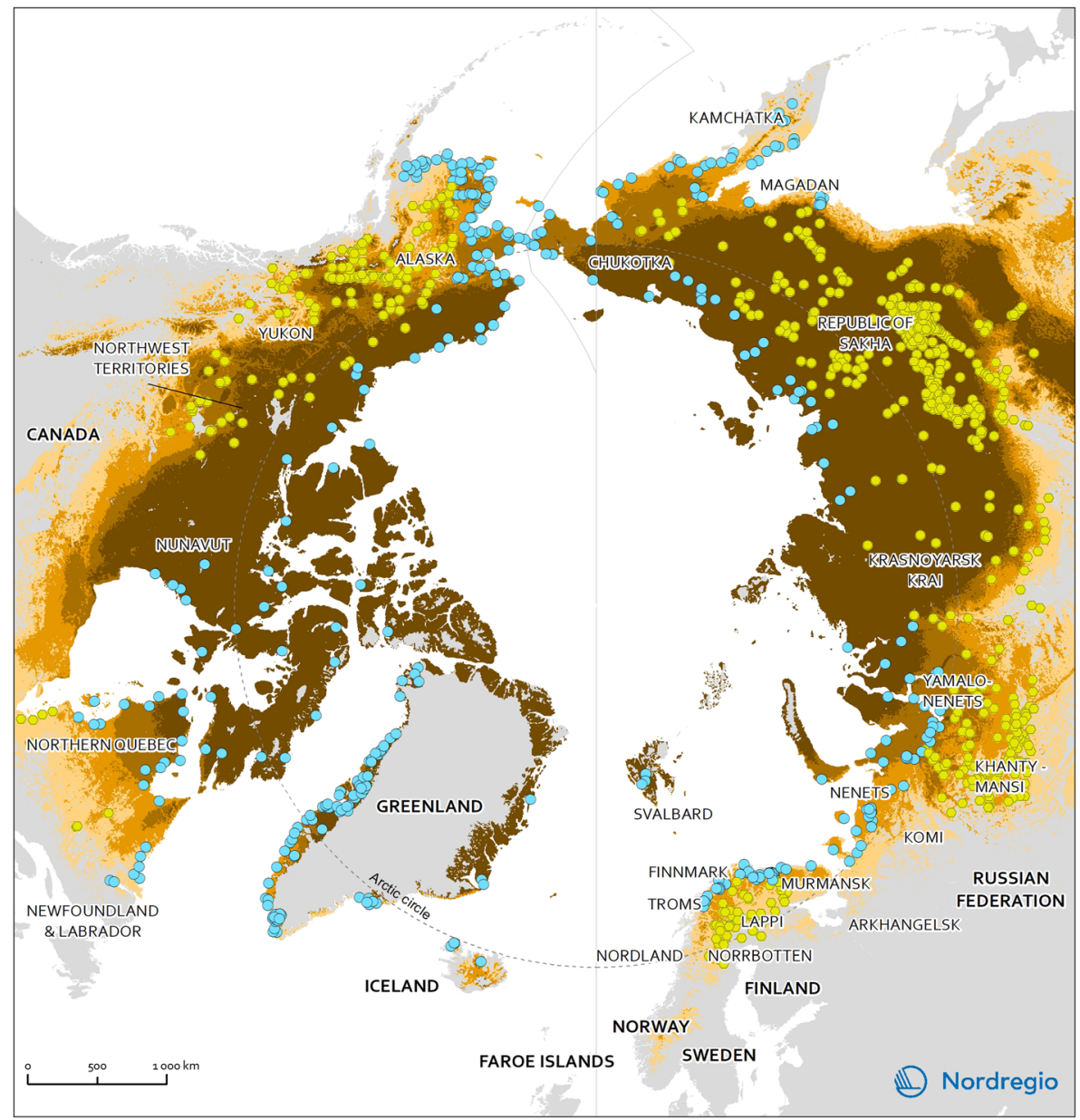

\section{Permafrost zones}

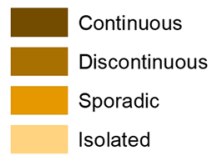

\section{Permafrost settlements}

- Inland

- Coastal

\section{Included in the Arctic Circumpolar Permafrost Region:}

US - Alaska;

CA - Yukon, Northwest Territories, Nunavut, Newfoundland \& Labrador, Northern Quebec;

GL - all;

IS - all;

NO - Nordland, Troms, Finnmark, Svalbard;

SE - Norrbotten;

FI - Lappi;

RU - Komi, Arkhangelsk, Nenets, Khanty-Mansi,Yamalo-Nenets,

Krasnoyarsk Krai, Republic of Sakha, Kamchatka, Magadan, Chukotka.

Fig. 1 Study area: permafrost settlements in the Arctic circumpolar permafrost region 
Quebec (Canada); Nordland, Troms, Finnmark, Svalbard (Norway); Norrbotten (Sweden); Lapland (Finland); Komi, Arkhangelsk, Khanty-Mansi, Yamalo-Nenets, Krasnoyarsk, Sakha Republic, Kamchatka, Magadan, Chukotka (Russian Federation); as well as Greenland and Iceland. We further refer to regions from the Russian Federation as the Russian Arctic, and regions from Sweden, Norway, and Finland as the Fennoscandian Arctic.

\section{Materials and methods}

\section{Settlements and permafrost extent}

Settlements in this study are defined according to the Arctic countries' National Statistical Institutes (NSI). We defined permafrost settlements as settlements located within the permafrost extent, as modeled by Obu et al. (2019). The permafrost extent is based on the modeled temperature at the top of the permafrost (TTOP model) for the period 2000-2016. The permafrost extent is available at the circum-Arctic scale, with a resolution of $1 \mathrm{~km}^{2}$. The permafrost zones are as follows: continuous (90-100\% area coverage), discontinuous (50$90 \%$ area coverage), and sporadic (0-50\% area coverage). In the definition of permafrost settlements, we used a socio-ecological system approach, which takes into account the fact that inhabitants strongly rely on services provided by ecosystems and are culturally deeply rooted in their local environment. Therefore, settlements within the sporadic permafrost zone are considered as permafrost settlements even if they are not directly built on permafrost.

To estimate the future of permafrost settlements, we used projected permafrost extents modeled by Hjort et al. (2018) using Representative Concentration Pathways (RCPs) 2.6, 4.5, and 8.5 for the period 2041-2060 (hereafter 2050). The model is binary and uses 30 arc-second grid cells $\left(1 \mathrm{~km}^{2}\right)$ to determine if permafrost is present or absent. We used the consensus index $\left(I_{c}\right)$, which classifies future permafrost extent into hazard zones (1, low; 2, medium; and 3, high hazard zones). When defining hazard zones, the consensus index considers the relative increase of the active layer thickness, ground ice content, ground temperature, permafrost thaw potential, surface properties (sediment/bedrock), fine-grained sediment content, frost susceptibility of ground material, and slope gradient.

We further classified permafrost settlements as coastal or inland. There is no strict definition of the Arctic coastal zone. We defined coastal zones as regions where interactions of sea and land processes occur, from both physical and human geography perspectives. To define permafrost coastal settlements, we used a raster of the Arctic coastal zone defined in the Arctic Circumpolar Vegetation Map (Raynolds et al. 2019), which we overlapped with the permafrost extent.

\section{Current and projected population}

The two main sources of demographic data in this study are population censuses and administrative and register data, at settlement level. The study uses the latest available population data from 2016 or 2017 (Table 1).

The number of people and settlements impacted by permafrost thaw by mid-century in the ACPR is a function of two factors: projected permafrost extent and demography. 
Table 1 List of demographic data sources used in this study

\begin{tabular}{|c|c|c|c|}
\hline Name & $\begin{array}{l}\text { Data } \\
\text { year }\end{array}$ & $\begin{array}{l}\text { Projection } \\
\text { year }\end{array}$ & Data sources \\
\hline Alaska & 2017 & 2015-2045 & $\begin{array}{l}\text { Alaska Department of Labor and Workforce Development (http://www. } \\
\text { labor.state.ak.us/) } \\
\text { U.S. Census Bureau (https://www.census.gov/en.html) }\end{array}$ \\
\hline Canada & 2016 & 2016-2035 & $\begin{array}{l}\text { Yukon Bureau of Statistics (http://www.eco.gov.yk.ca/stats/ybs.html) } \\
\text { NWT Bureau of Statistics (http://www.statsnwt.ca/) } \\
\text { Nunavut Bureau of Statistics (https://www.gov.nu. } \\
\text { ca/eia/information/nunavut-bureau-statistics) } \\
\text { Newfoundland \& Labrador Statistics Agency (https://www.stats.gov.nl. } \\
\text { ca/) } \\
\text { Statistics Canada (http://www.statcan.gc.ca/eng/start) }\end{array}$ \\
\hline Greenland & 2017 & $2017-2040$ & Statistics Greenland (http://www.stat.gl/) \\
\hline Iceland & 2017 & 2016-2066 & Statistics Iceland (http://www.statice.is/) \\
\hline Faroe Islands & 2017 & $2016-2040$ & Statistics Faroe Islands (http://www.hagstova.fo/en) \\
\hline Norway & 2017 & $2017-2040$ & Statistics Norway (http://www.ssb.no/en/) \\
\hline Sweden & 2016 & $2017-2040$ & Statistics Sweden (http://www.scb.se/en/) \\
\hline Finland & 2016 & $2017-2040$ & Statistics Finland (http://www.stat.fi/index_en.html) \\
\hline $\begin{array}{l}\text { Russian } \\
\text { Federation }\end{array}$ & 2017 & 2019-2036 & Federal States Statistics Service (http://www.gks.ru/) \\
\hline
\end{tabular}

The methodologies for projecting population and permafrost are quite separate, and do not take trends in the other into account. We used the population projections provided by the national and regional statistical offices and synthesized by Heleniak (2019), and extrapolated the annual rate of change to the year 2050. The standard practice used by the national and regional statistical offices for projecting population change is the cohort-component method. The components of population change-fertility, mortality, and migration - are applied to the cohorts, or the age-sex structure of the population. Population projections at the settlement level are scarce, thus we applied the projected regional rates of change to the settlement level, assuming that all permafrost settlements within a region will change at the same rate over the projection period.

\section{Limitations of the study}

We used two models of permafrost extent to estimate the number of permafrost settlements. While the model resolutions are the same $\left(1 \mathrm{~km}^{2}\right)$, the models include different parameters to measure the probabilities of permafrost to occur in one place. This might impact our results when comparing ground conditions for current and projected permafrost settlements.

Additionally, projecting future demographic trends in the Arctic is difficult because of their small population sizes and their economies based on natural resources, which are subject to boom-and-bust cycles. To overcome this, we used regional population projections when available. On the one hand, it provides more 
detail and nuance than the national projections. However, it also increases errors by combining different projection models. Models mainly differ in the amount of detail involved in the projected population and the length of the projection period (Heleniak 2019). Moreover, the demographic variability observed at the regional level in Arctic societies (Hamilton et al. 2018) confirms that the use of regional rates to project population at the settlement level might lead to over- or underestimation of the future population. However, with exception of Canada, there are no population projections available at the settlement level.

\section{Results}

\section{Population on permafrost}

In 2017, there were 4,942,685 inhabitants in the ACPR, residing in 1162 permafrost settlements (Table 2). Most of the population in the ACPR was concentrated in a few large permafrost settlements. A majority of the permafrost inhabitants lived in 511 settlements located in zones of sporadic permafrost (Table 2). However, most of the permafrost settlements were in zones of continuous permafrost, where $18.6 \%$ of the permafrost inhabitants lived. A few settlements were in zones of discontinuous permafrost. There were large regional differences in the distribution of permafrost settlements. The majority of the settlements in the Russian Arctic were located on continuous permafrost, while most of the permafrost settlements in the Fennoscandian Arctic were located in zones of sporadic permafrost (Appendix Table 5).

Of all permafrost settlements, 32.6\% were coastal, where 1,099,186 inhabitants resided (Table 2). The majority of the coastal inhabitants were living in zones of sporadic permafrost, whereas $10 \%$ were living in zones of continuous permafrost. In Greenland, all settlements were coastal. In Canada and Alaska, almost half of the permafrost settlements were along the coastline, all located on continuous permafrost. In the Russian Arctic, permafrost settlements were mostly situated inland on continuous permafrost, except for the Nenets region, where all permafrost settlements were coastal, in zones of sporadic permafrost.

Table 2 Number of permafrost settlements and inhabitants by permafrost type in the Arctic Circumpolar Permafrost Region in 2017. Coastal settlements and population are included in the numbers of permafrost settlements and population

\begin{tabular}{lllll}
\hline & $\begin{array}{l}\text { Settlements on } \\
\text { permafrost }\end{array}$ & $\begin{array}{l}\text { Population on } \\
\text { permafrost }\end{array}$ & $\begin{array}{l}\text { Coastal settlements } \\
\text { on permafrost }\end{array}$ & $\begin{array}{l}\text { Coastal population } \\
\text { on permafrost }\end{array}$ \\
\hline Sporadic & 511 & $3,286,723$ & 205 & 876,896 \\
Discontinuous & 162 & 733,485 & 79 & 108,896 \\
Continuous & 489 & 922,477 & 95 & 113,394 \\
Total & 1162 & $4,942,685$ & 379 & $1,099,186$ \\
\hline
\end{tabular}




\section{Population impacted by the loss of permafrost}

The number of people living on permafrost in the ACPR is expected to decrease, from 4.9 million in 2017 to 1.7 million in 2050 . This means that 3.3 million people in the ACPR live in settlements where permafrost will degrade and ultimately disappear by 2050 (Table 3). The area with the largest population on permafrost by 2050 will remain the Russian Arctic (Khanty-Mansi, Sakha Republic, Murmansk, and Yamalo-Nenets).

In 2050, 1.7 million people will live in 628 permafrost settlements (Table 3). Although there were only few settlements located in areas with permafrost in Sweden, Finland, and Iceland, by 2050 there will no longer be any permafrost settlements in these countries (Fig. 2, Appendix Table 6).

Damage caused by permafrost thaw in permafrost settlements will differ depending on the permafrost's vulnerability to thawing, as summarized by the hazard zones. Among the settlements remaining on permafrost in 2050, 41.7\% (RCP 4.5) will be in high hazard zones, where the consequences of permafrost thaw will be most severe (Table 3). This will mainly affect settlements in the Russian Arctic and in Alaska (Fig. 2, Appendix Table 7). By contrast, 20.9\% (RCP 4.5) of the settlements remaining on permafrost in 2050 will be least impacted by permafrost thaw, mainly in Greenland and Canada. While $43.0 \%$ (RCP 4.5) of the permafrost inhabitants will live in low hazard zones, $32.0 \%$ will be in high hazard zones, where permafrost is likely to be extremely degraded. In comparison to inland settlements, a larger proportion of coastal settlements will become permafrost-free by 2050, although fewer of these coastal settlements will be in high hazard zones (Table 3). By 2050, 323,362 people will live in a coastal permafrost settlement, $42.7 \%$ of them in a high hazard zone (Table 3 ).

Almost all the population currently living in areas of sporadic permafrost in the ACPR will be living in permafrost-free areas (Table 4). More than half of the population currently living in areas of discontinuous or continuous permafrost will be living in medium and high hazard zones (Table 4).

\section{Largest settlements impacted by the loss of permafrost}

Most of the permafrost settlements in the ACPR were small, with a median size of 622 inhabitants. However, there were 123 permafrost settlements with more than 5000 inhabitants in 2017. These large settlements had a median population of 12,696 ( $\mathrm{min}=$ 5024 , $\max =360,590$ ), and a total of 4 million inhabitants. Eighty-five percent of the large permafrost settlements were in the Russian Arctic. The population in the large settlements is projected to increase by $3.5 \%$ by 2050 . In total, $65.8 \%$ of these large settlements were in zones of sporadic permafrost, while $34.1 \%$ were in zones of discontinuous and continuous permafrost.

Surgut, Yakutsk, Murmansk, Nizhnevartovsk, and Norilsk are the five largest settlements in the Russian Arctic that will have to adapt to the loss of permafrost. In 2017, 1.4 million people lived in these five settlements, where the population is projected to increase by $3.9 \%$. Surgut, Murmansk, and Nizhnevartovsk are in the sporadic and discontinuous permafrost zones. While it is not possible to determine from the permafrost maps utilized in this study to what extent the settled areas are currently underlain by permafrost, the regions around the settlements will become permafrost-free by 2050. Yakutsk and Norilsk are located on continuous permafrost 


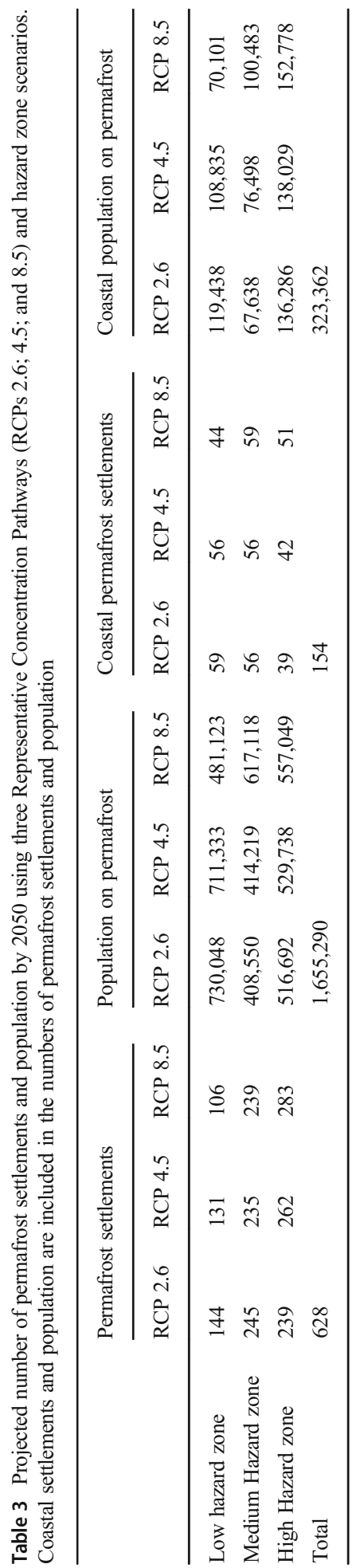




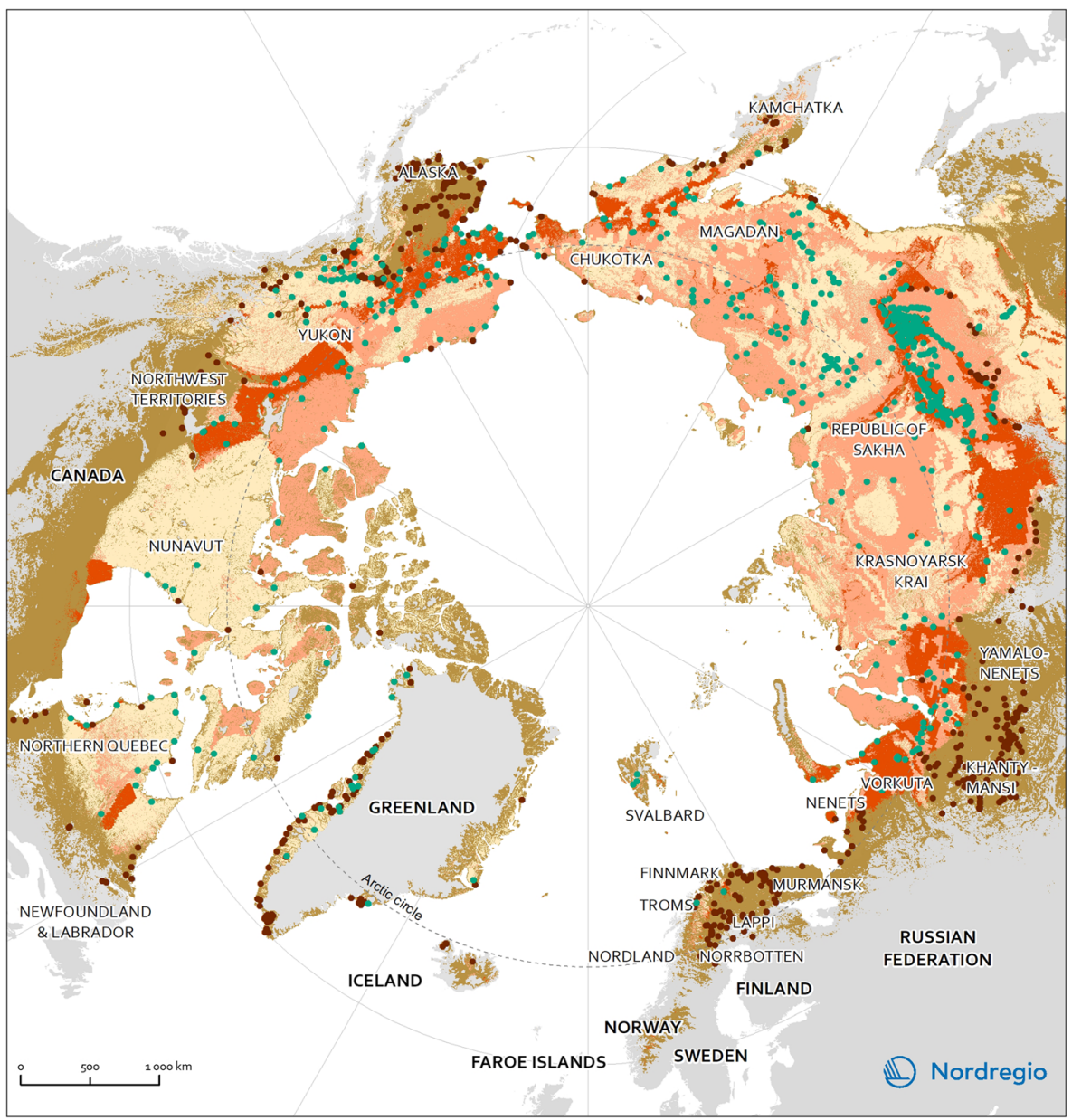

\section{Permafrost extent}

Current:

Permafrost extent 2016

\section{Permafrost settlements}

Future:

hazard zones (2060, RCP 4.5)

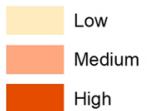

Permafrost settlements by 2060

Permafrost settlements in 2017

Fig. 2 Settlements at risk due to permafrost thaw by 2060

and will be more affected by permafrost thaw, although they will be in low hazard zones. Yellowknife in Canada is the largest settlement on permafrost in the Canadian Arctic. Its population of 19,596 in 2017 is expected to grow by $20.5 \%$ by 2050 . Yellowknife is located on discontinuous permafrost, and will be in a high hazard zone by 2050 .

Due to permafrost thaw, $65.0 \%$ of the large settlements of the ACPR will become permafrost-free by 2050 (RCP 4.5), and their 3 million inhabitants will have to contend with changes related to the loss of permafrost. Among the 43 large settlements that will remain on permafrost by 2050, 20 are in high hazard zones, where the consequences of 
Table 4 Proportion of the population within type of permafrost area that will be affected by permafrost thaw by 2050 (RCP 4.5)

\begin{tabular}{|c|c|c|c|c|c|}
\hline \multirow{2}{*}{$\begin{array}{l}\text { Permafrost } \\
\text { type } 2017\end{array}$} & \multirow{2}{*}{$\begin{array}{l}\text { Population } \\
2017\end{array}$} & \multicolumn{4}{|c|}{ Proportion of the population affected by permafrost thaw by $2050(\%)$} \\
\hline & & $\begin{array}{l}\text { Permafrost-free } \\
\text { zone }\end{array}$ & $\begin{array}{l}\text { Low hazard } \\
\text { zone }\end{array}$ & $\begin{array}{l}\text { Medium hazard } \\
\text { zone }\end{array}$ & $\begin{array}{l}\text { High hazard } \\
\text { zone }\end{array}$ \\
\hline Sporadic & $3,286,723$ & 95,6 & 0,7 & 0,3 & 3,5 \\
\hline Discontinuous & 733,485 & 12,8 & 38,9 & 24,8 & 23,5 \\
\hline Continuous & 922,477 & 3,3 & 43,9 & 25,2 & 27,7 \\
\hline
\end{tabular}

permafrost thaw will be the most profound. Of these 20 settlements, 19 are in the Russian Arctic and one is in Canada.

\section{Variability in the impacts depending on the climate trajectory}

The results we describe consider a mitigation emission scenario (RCP 4.5), suggesting a stabilization of atmospheric concentrations near 2060 to $4.5 \mathrm{~W} / \mathrm{m}^{2}$ (or $650 \mathrm{ppm} \mathrm{CO}_{2}$ equivalent). Following a "business as usual" scenario (RCP 8.5), the consequences of permafrost thaw on permafrost settlements and population will be worse. In such a scenario, the number of permafrost settlements that will be in high hazard zones by 2050 will be $8 \%$ higher and the permafrost population $5 \%$ higher (Table 3). The consequences for coastal settlements will be more severe, with a $21 \%$ increase in the number of permafrost settlements in high hazard zones and an $11 \%$ increase in permafrost population in these zones. The consequences of permafrost thaw on permafrost settlements and population will be reduced if greenhouse gases emissions are low and atmospheric concentrations stabilize earlier (RCP 2.6). The number of permafrost settlements located in high hazard zones will be $10 \%$ lower, and the permafrost population will fall by $3 \%$ (Table 3 ).

\section{Discussion}

\section{Adaptation to permafrost-free environment}

We show that close to 3.3 million people living in the ACPR will be affected by the thawing - and eventual loss — of permafrost. Three percent of the settlements that are currently located on continuous permafrost will become permafrost-free, meaning that the settlements will have to face the costs of rebuilding and renovating public and private infrastructure damaged by permafrost thaw. The majority of permafrost inhabitants (3.1 million) live in zones of sporadic permafrost. While almost all of the people living in zones of sporadic permafrost will live in a permafrost-free area in 2050, the costs related to permafrost thaw in these settlements might not be as high if they are not directly located on permafrost. However, people living on sporadic permafrost will be impacted by the changes affecting the permafrost ecosystems surrounding their settlements, which will trigger transitions in socio-ecological systems (Schuur and Mack 
2018). By contrast, settlements in discontinuous or continuous permafrost zones that will be in high hazard zones in 2050 will face significant costs associated with adapting to permafrost thaw. Damage to infrastructure due to permafrost thaw is caused by both ground subsidence and a decrease in the ground's bearing capacity, leading to cracks, deformations, and the collapse of built structures (Streletskiy et al. 2012, 2019). This impacts the useful life of infrastructure, reducing it by $0.2 \%$ in sporadic permafrost and by $0.9 \%$ in continuous permafrost per ${ }^{\circ} \mathrm{C}$ increase (Larsen et al. 2008). In the Russian Arctic, the most significant reduction in bearing capacity is expected in the discontinuous and southern fringes of continuous permafrost zones (Shiklomanov et al. 2017a), in which we calculate that 472 settlements and 1.5 million people are located.

\section{Adaptation in settlements remaining on permafrost}

For the settlements remaining on permafrost, the consequences of permafrost thaw will vary depending on the hazard zone on which they are located. In 2050, half a million inhabitants on permafrost will live in high hazard zones, where the consequences of permafrost thaw will be most severe, mainly in the Russian Arctic and in Alaska. These areas are in thawunstable zones characterized by relatively high ground-ice content and thick deposits of frost-susceptible sediments (Hjort et al. 2018). By contrast, permafrost thaw will be a minor concern for slightly more than 700,000 permafrost inhabitants who will live in low hazard zones, mostly in Greenland and in Canada, where a large number of people currently live in settlements built on bedrock.

\section{Adaptation in coastal permafrost settlements}

We show that coastal settlements are proportionally more exposed to permafrost thaw than inland settlements. Flooding and coastal erosion are major risks for many of these settlements, threatening the viability of some settlements, damaging important cultural heritage sites, and compromising municipal infrastructure and water supply (Nelson et al. 2001; Shiklomanov et al. 2017b; Warren et al. 2005). Coastal settlements will suffer from both ground subsidence and coastal erosion. While ground subsidence is a parameter included in the permafrost projection model (Hjort et al. 2018), coastal erosion is not. Along the Arctic coast, coastal erosion rates average $0.5 \mathrm{~m} \mathrm{a}^{-1}$, with high geographic variability (Lantuit et al. 2012). Coastal erosion is a real threat for the 379 coastal settlements on permafrost and their 1 million inhabitants. Several communities have already been forced to relocate, while others have just left vulnerable settlements (Bronen 2010; Hamilton et al. 2016). However, the settlements most threatened by erosion in Alaska do not yet show any evidence of increased outmigration (Hamilton et al. 2018).

\section{Adaptation capacity}

Settlements in the ACPR differ considerably in terms of both population size and physical ground conditions. Despite their differences in terms of population size, infrastructure, and economy (Hamilton et al. 2018), Arctic settlements face similar challenges related to the loss of permafrost. The impacts mainly relate to damage to infrastructure and changes in the livelihoods of people living on permafrost. These impacts might have significant consequences on the future economic and social development of the Arctic (Streletskiy et al. 
2012). Adaptation capacity to permafrost-free environments will vary depending on the type of permafrost and potential hazard zone on which the settlements are currently located, as well as the settlements' size and economic situation. Larger settlements located in high hazard zones related to permafrost thaw are mostly located in the Russian Arctic, and in some ACPR regions with the strongest economies (as measured by the Growth Regional Product (GRP)). The economic situation in these regions may help to offset some mitigation costs (Suter et al. 2019). However, some regions with large settlements and weaker economies located in high hazard zones will incur high annual costs to address damages related to permafrost thaw. This is the case for the Northwest Territories in Canada, where the annual costs might be as high as $1.5 \%$ of GRP (Suter et al. 2019).

\section{Conclusion}

This is the first demographic study assessing the population living on permafrost and the impact of permafrost thaw on the population living in the Arctic Circumpolar Permafrost Region. In 2017, close to five million inhabitants lived in 1162 permafrost settlements in the ACPR. As a result of permafrost thaw, many of these inhabitants will live in permafrost-free areas by 2050. The total number of inhabitants on permafrost is projected to decrease by $61.2 \%$ - from 4.9 million to 1.7 million by 2050 . Permafrost will degrade and ultimately disappear in 534 permafrost settlements, impacting the life of 3.3 million inhabitants. Settlements remaining on permafrost by 2050 will also have to adapt to permafrost thaw, as $42 \%$ of them will be located in high hazard zones. The impacts will vary depending on the future climate trajectory, the permafrost type and hazard zones in which settlements are located, and the extent to which settlements can adapt in the remaining time before the permafrost thaws.

\section{Data}

The data used is listed in the references, tables, supporting information, and the ZENODO repository https://doi.org/10.5281/ZENODO.4266017 (Wang and Ramage 2020).

\section{Appendix 1}

Table 5 Number of settlements within each permafrost extent zone per country in 2017

\begin{tabular}{lllllllll}
\hline & Alaska & Canada & Finland & Greenland & Iceland & Norway & Russia & Sweden \\
\hline Sporadic & 123 & 45 & 21 & 34 & 4 & 20 & 241 & 23 \\
Discontinuous & 50 & 19 & 0 & 22 & 0 & 0 & 71 & 0 \\
Continuous & 19 & 44 & 0 & 23 & 0 & 2 & 401 & 0 \\
\hline
\end{tabular}




\section{Appendix 2}

Table 6 Number of settlements and people in the permafrost zone of the ACPR per region in 2017 and by 2050

\begin{tabular}{|c|c|c|c|c|c|}
\hline Country & Region & $\begin{array}{l}\text { Settlements } \\
2017\end{array}$ & $\begin{array}{l}\text { Population } \\
2017\end{array}$ & $\begin{array}{l}\text { Settlements } \\
2050\end{array}$ & $\begin{array}{l}\text { Population } \\
2050\end{array}$ \\
\hline \multirow[t]{16}{*}{ Alaska } & All ACPR regions & 192 & 169,481 & 77 & 29,173 \\
\hline & Bethel & 32 & 17,985 & 0 & 0 \\
\hline & Bristol Bay & 1 & 309 & 0 & 0 \\
\hline & Denali & 4 & 1574 & 2 & 182 \\
\hline & Dillingham & 9 & 3982 & 0 & 0 \\
\hline & Fairbanks North Star & 17 & 96,665 & 2 & 3182 \\
\hline & Haines & 1 & 265 & 0 & 0 \\
\hline & $\begin{array}{l}\text { Kusilvak CA (Wade } \\
\text { Hampton) }\end{array}$ & 13 & 8180 & 0 & 0 \\
\hline & Lake and Peninsula & 2 & 146 & 0 & 0 \\
\hline & Matanuska-Susitna & 3 & 307 & 2 & 525 \\
\hline & Nome & 20 & 10,798 & 10 & 8743 \\
\hline & North Slope & 8 & 8745 & 6 & 2534 \\
\hline & Northwest Arctic & 11 & 7374 & 11 & 9118 \\
\hline & Southeast Fairbanks & 19 & 6520 & 14 & 2495 \\
\hline & Valdez-Cordova & 15 & 1557 & 7 & 258 \\
\hline & Yukon-Koyukuk & 37 & 5074 & 23 & 2136 \\
\hline \multirow[t]{6}{*}{ Canada } & All ACPR regions & 108 & 155,714 & 59 & 102,725 \\
\hline & Newfoundland and Labrador & 9 & 21,432 & 0 & 0 \\
\hline & Northwest Territories & 33 & 41,425 & 19 & 34,051 \\
\hline & Nunavut & 24 & 34,944 & 17 & 44,746 \\
\hline & Quebec & 22 & 26,607 & 13 & 18,693 \\
\hline & Yukon & 20 & 31,306 & 10 & 5235 \\
\hline \multirow[t]{2}{*}{ Finland } & All ACPR regions & 21 & 76,536 & 0 & 0 \\
\hline & Lappi & 21 & 76,536 & 0 & 0 \\
\hline \multirow[t]{13}{*}{ Greenland } & All ACPR regions & 79 & 54,257 & 17 & 12,554 \\
\hline & Aasiaat & 1 & 3112 & 0 & 0 \\
\hline & Ammasalik & 6 & 2930 & 1 & 184 \\
\hline & Illoqqortoormiut & 2 & 380 & 1 & 5 \\
\hline & Ilulissat & 5 & 4908 & 2 & 4179 \\
\hline & Ivittuut & 1 & 1 & 0 & 0 \\
\hline & Kangaatsiaq & 5 & 1182 & 1 & 242 \\
\hline & Maniitsoq & 4 & 3143 & 0 & 0 \\
\hline & Nanortalik & 6 & 283 & 0 & 0 \\
\hline & Narsaq & 6 & 1674 & 0 & 0 \\
\hline & Nuuk & 4 & 17,851 & 1 & 3 \\
\hline & Paamiut & 2 & 1530 & 0 & 0 \\
\hline & Qaanaaq & 4 & 755 & 2 & 621 \\
\hline
\end{tabular}


Table 6 (continued)

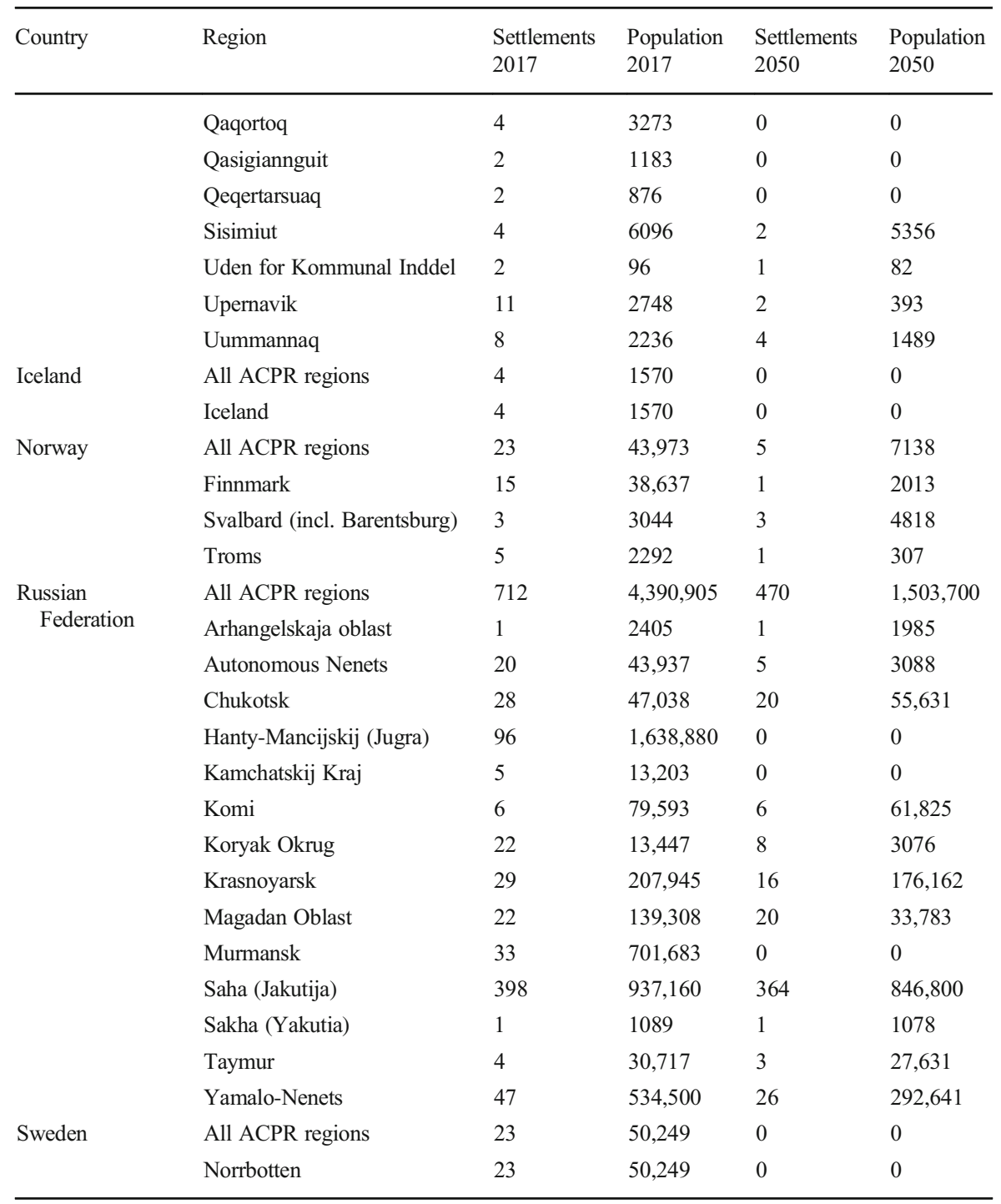




\section{Appendix 3}

Table 7 Projected number of settlements within each permafrost hazard zones per country by 2050. The projections follow the RCP 4.5 scenario

\begin{tabular}{lllllllll}
\hline & Alaska & Canada & Finland & Greenland & Iceland & Norway & Russia & Sweden \\
\hline Low hazard & 20 & 32 & 0 & 15 & 0 & 0 & 64 & 0 \\
Medium hazard & 28 & 16 & 0 & 2 & 0 & 3 & 186 & 0 \\
High hazard & 29 & 11 & 0 & 0 & 0 & 1 & 221 & 0 \\
\hline
\end{tabular}

Open Access This article is licensed under a Creative Commons Attribution 4.0 International License, which permits use, sharing, adaptation, distribution and reproduction in any medium or format, as long as you give appropriate credit to the original author(s) and the source, provide a link to the Creative Commons licence, and indicate if changes were made. The images or other third party material in this article are included in the article's Creative Commons licence, unless indicated otherwise in a credit line to the material. If material is not included in the article's Creative Commons licence and your intended use is not permitted by statutory regulation or exceeds the permitted use, you will need to obtain permission directly from the copyright holder. To view a copy of this licence, visit http://creativecommons.org/licenses/by/4.0/.

\section{References}

Allard, M., Lemay, M., Barrette, C., L’Hérault, E., Sarrazin, D., Bell, T., \& Doré, G. (2012). Permafrost and climate change in Nunavik and Nunatsiavut: Importance for municipal and transportation infrastructures (Nunavik and Nunatsiavut: From science to policy. An integrated regional impact study (IRIS) of climate change and modernization, p. 27).

Berkes, F., \& Jolly, D. (2000). Adapting to climate change: Social-ecological resilience in a Canadian Western Arctic community. Ecology and Society. https://doi.org/10.5751/ES-00342-050218.

Biskaborn, B. K., Smith, S. L., Noetzli, J., Matthes, H., Vieira, G., Streletskiy, D. A., Schoeneich, P., Romanovsky, V. E., Lewkowicz, A. G., Abramov, A., Allard, M., Boike, J., Cable, W. L., Christiansen, H. H., Delaloye, R., Diekmann, B., Drozdov, D., Etzelmüller, B., Grosse, G., et al. (2019). Permafrost is warming at a global scale. Nature Communications, 10(1), 264. https://doi.org/ 10.1038/s41467-018-08240-4.

Bronen, R. (2010). Forced migration of Alaskan indigenous communities due to climate change. In Environment, forced migration and social vulnerability (pp. 87-98). Berlin: Springer.

Duhaime, G., Chabot, M., Fréchette, P., Robichaud, V., \& Proulx, S. (2004). The impact of dietary changes among the inuit of Nunavik (Canada): A socioeconomic assessment of possible public health recommendations dealing with food contamination. Risk Analysis, 24(4), 1007-1018. https://doi.org/10.1111/j. 0272-4332.2004.00503.x.

Einarsson, N., Nymand Larsen, J., Nilsson, A. and Young, O.R., 2004. Arctic human development report. Stefansson Arctic Institute.

Ford, J. D., \& Pearce, T. (2010). What we know, do not know, and need to know about climate change vulnerability in the western Canadian Arctic: A systematic literature review. Environmental Research Letters, 5(1), 14008.

Ford, J. D., Pearce, T., Duerden, F., Furgal, C., \& Smit, B. (2010). Climate change policy responses for Canada's Inuit population: The importance of and opportunities for adaptation. Global Environmental Change, 20(1), 177-191.

Gruber, S. (2012). The cryosphere derivation and analysis of a high-resolution estimate of global permafrost zonation. Cryosphere, 6, 221-233. https://doi.org/10.5194/tc-6-221-2012.

Hamilton, L. C., Saito, K., Loring, P. A., Lammers, R. B., \& Huntington, H. P. (2016). Climigration? Population and climate change in Arctic Alaska. Population and Environment, 38(2), 115-133. 
Hamilton, L. C., Wirsing, J., \& Saito, K. (2018). Demographic variation and change in the Inuit Arctic. Environmental Research Letters, 13(11) IOP Publishing, 115007. https://doi.org/10.1088/1748-9326/ aae7ef.

Heleniak, T. (2019). The future of the Arctic populations. Polar Geography. https://doi.org/10.1080/ 1088937X.2019.1707316.

Hjort, J., Karjalainen, O., Aalto, J., Westermann, S., Romanovsky, V. E., Nelson, F. E., Etzelmüller, B., \& Luoto, M. (2018). Degrading permafrost puts Arctic infrastructure at risk by mid-century. Nature Communications, 9(1), 5147. https://doi.org/10.1038/s41467-018-07557-4.

Lantuit, H., Overduin, P. P., Couture, N., Wetterich, S., Aré, F., Atkinson, D., Brown, J., Cherkashov, G., Drozdov, D., Forbes, D. L., \& Graves-Gaylord, A. (2012). The Arctic coastal dynamics database: A new classification scheme and statistics on Arctic permafrost coastlines. Estuaries and Coasts, 35(2), 383-400.

Larsen, P. H., Goldsmith, S., Smith, O., Wilson, M., Strzepek, K., Chinowsky, P., \& Saylor, B. (2008). Estimating future costs for Alaska public infrastructure at risk from climate change. Global Environmental Change, 18(3), 442-457. https://doi.org/10.1016/j.gloenvcha.2008.03.005.

Nelson, F. E., Anisimov, O. A., \& Shiklomanov, N. I. (2001). Subsidence risk from thawing permafrost. Nature, 410(6831), 889. https://doi.org/10.1038/35073746.

NSIDC (2019). Arctic people | National Snow and ice data center. The National Snow and Ice Data Center. https://nsidc.org/cryosphere/arctic-meteorology/arctic-people.html.

Nymand Larsen, J. (Ed.). (2014). Arctic human development report: Regional processes and global linkages. Nordic Council of Ministers.

O'Garra, T. (2017). Economic value of ecosystem services, minerals and oil in a melting Arctic: A preliminary assessment. Ecosystem Services, 24, 180-186. https://doi.org/10.1016/j.ecoser.2017.02.024.

Obu, J., Westermann, S., Bartsch, A., Berdnikov, N., Christiansen, H. H., Dashtseren, A., Delaloye, R., Elberling, B., Etzelmüller, B., Kholodov, A., Khomutov, A., Kääb, A., Leibman, M. O., Lewkowicz, A. G., Panda, S. K., Romanovsky, V., Way, R. G., Westergaard-Nielsen, A., Wu, T., et al. (2019). Northern hemisphere permafrost map based on TTOP modelling for 2000-2016 at $1 \mathrm{~km} 2$ scale. Earth-Science Reviews, 193, 299-316. https://doi.org/10.1016/j.earscirev.2019.04.023.

Raynolds, M. K., Walker, D. A., Balser, A., Bay, C., Campbell, M., Cherosov, M. M., Daniëls, F. J., Eidesen, P. B., Ermokhina, K. A., Frost, G. V., \& Jedrzejek, B. (2019). A raster version of the circumpolar Arctic vegetation map (CAVM). Remote Sensing of Environment, 232, 111297. https://doi.org/10.1016/j.rse. 2019.111297.

Schuur, E. A. G., \& Mack, M. C. (2018). Ecological response to permafrost thaw and consequences for local and global ecosystem services. Annual Review of Ecology, Evolution, and Systematics, 49(1), 279-301. https://doi.org/10.1146/annurev-ecolsys-121415-032349.

Sharma, S. (2010). Assessing diet and lifestyle in the Canadian Arctic Inuit and Inuvialuit to inform a nutrition and physical activity intervention programme: Nutrition transition in Arctic Canada. Journal of Human Nutrition and Dietetics, 23, 5-17. https://doi.org/10.1111/j.1365-277X.2010.01093.x.

Shiklomanov, N. I., Streletskiy, D. A., Swales, T. B., \& Kokorev, V. A. (2017a). Climate change and stability of urban infrastructure in Russian permafrost regions: Prognostic assessment based on GCM climate projections. Geographical Review, 107(1), 125-142. https://doi.org/10.1111/gere.12214.

Shiklomanov, N. I., Streletskiy, D. A., Grebenets, V. I., \& Suter, L. (2017b). Conquering the permafrost: Urban infrastructure development in Norilsk, Russia. Polar Geography, 40(4), 273-290. https://doi.org/ 10.1080/1088937X.2017.1329237.

Streletskiy, D. A., Shiklomanov, N. I., \& Nelson, F. E. (2012). Permafrost, infrastructure, and climate change: A GIS-based landscape approach to geotechnical modeling. Arctic, Antarctic, and Alpine Research, 44(3), 368-380. https://doi.org/10.1657/1938-4246-44.3.368.

Streletskiy, D. A., Suter, L. J., Shiklomanov, N. I., Porfiriev, B. N., \& Eliseev, D. O. (2019). Assessment of climate change impacts on buildings, structures and infrastructure in the Russian regions on permafrost. Environmental Research Letters, 14(2), 025003. https://doi.org/10.1088/1748-9326/aaf5e6.

Suter, L. J., Streletskiy, D. A., \& Shiklomanov, N. I. (2019). Assessment of the cost of climate change impacts on critical infrastructure in the circumpolar Arctic. Polar Geography. https://doi.org/10.1080/1088937X. 2019.1686082 .

Van Everdingen, R. O. (2005). Multi-language glossary of permafrost and related ground-ice. International Permafrost Association, Terminology Working Group.

Wang, S., \& Ramage, J. (2020). Population in the Arctic circumpolar permafrost region at settlement level. Zenodo. https://doi.org/10.5281/ZENODO.4266017.

Warren, J. A., Berner, J. E., \& Curtis, T. (2005). Climate change and human health: Infrastructure impacts to small remote communities in the north. International Journal of Circumpolar Health, 64(5), 487-497. https://doi.org/10.3402/ijch.v64i5.18030. 
Wesche, S. D., \& Chan, H. M. (2010). Adapting to the impacts of climate change on food security among Inuit in the Western Canadian Arctic. EcoHealth, 7(3), 361-373. https://doi.org/10.1007/s10393-010-0344-8.

Publisher's note Springer Nature remains neutral with regard to jurisdictional claims in published maps and institutional affiliations. 